\title{
Preventing acid mine drainage from mine tailings
}

\author{
M. Cristina Vila, J. Soeiro de Carvalho, A. Futuro da Silva \\ \& A. Fiúza \\ CIGAR - Centro de Investigação em Geoambiente e Recursos, \\ Mining Department of Faculty of Engineering of University of Porto, \\ Portugal
}

\begin{abstract}
Mining activity always has high impact on its surroundings, being waste deposition the cause of multiple and complex problems to the environment. One of them is Acid Mine Drainage (AMD), causing acid water percolation through large areas in the mine site. Portugal was a prosper tungsten producer from the beginning of the 20th century, having its apogee during World War II. Nowadays there are millions of tons of mine residues deposited in either stock piles or in tailing dams, most of them abandoned, and only one mine still producing tungsten. Available experimental tests to evaluate the acid production potential are listed and commented. Fresh tailings from the still active Panasqueira mine were used as a case study. Laboratory scale tests allowed us to predict the AMD potential as well as its kinetics, which constitutes a very important tool in tailings management. Pilot scale experiments tested the effect of different cover types, including an organic compound host of oxygen consumer microorganisms, in preventing and reducing AMD.

Keywords: Acid Mine Drainage, tailings, sulphide ores, soils and groundwater contamination, heavy metals, leachate.
\end{abstract}

\section{Introduction}

\subsection{Sulphide mine waste and tailings}

It is known that mining industry causes negative impacts in its surrounding area. The production of acid mine drainage (AMD) has long been known to occur in 
various mining sites. Mining produces large amounts of waste rock, i.e. rock with metal contents too low to be economically recoverable. Waste rock is usually stored in large piles. When sulphides are present, AMD can be produced due to sulphide oxidation. This group of minerals is present, in significant percentages, in most of the mines, not only in sulphide ores, but also in the host rock associated with most types of mining activity, be it tungsten or coal. Sulphides are oxidized when in contact with water and oxygen through a series of chemical reactions which are moderately exothermic and is characterized by high concentrations of oxygen, high temperature, low $\mathrm{pH}$ and bacterial activity. It is known that minerals located in the saturated zone (below the freatic level) are chemically protected from oxidation. Therefore, in a generic way, in environments without oxygen, such as ground water, the sulphides are chemically stable, having high chemical stability. Prior mining, oxidation of these minerals and the formation of sulphuric acid occurs only trough natural weathering processes. The oxidation and consequent release of acid and mobilization of metals in undisturbed ore bodies is slow. As soon as mining starts, oxidation begins. The ore is brought to surface and processed. Here the same chemical reactions happen at a much faster rate. A large volume of piled waste, overburden rock and finer materials from processing deposited in dams, contacts a new oxygen rich environment, immediately starting oxidation. The new variable size granular materials, of greater specific surface, are now more exposed to air and water, increasing acid generation, as a series of bio-geo-chemical reactions develop. The mineralogy of waste material is another variable that influences the acid production potential of waste piles. If, for instance, carbonates $\left(\mathrm{CaCO}_{3}\right)$ exist the $\mathrm{pH}$ will be kept near to neutrality, the dissolved metals will precipitate, not suffering significant transport. The $\mathrm{pH}$ of the environment results of the balance between the acid production resultant of oxidation of sulphides and the chemical reactions of consumption, and in turn influences the mobility of dissolved metals. If the metals are susceptive of dissolution they will be quickly dissolved, $\mathrm{pH}$ falling down to low values and forming an acid front. This degrades water quality, either superficial or underground, generating acidification, metal accumulation in sediments and in water, affecting species and their habitat, causing instability in ecosystems.

\subsection{Panasqueira mine: a case study}

Panasqueira is an important tin and wolfram mine located in central Portugal, in the vicinity of the Serra da Estrela mountains. Panasqueira mine belongs to the Central Iberian Zone, which is composed by the Beira formation Schist of the Precambrian - Cambrian superior. The intrusive hercinic granite system of the North of Portugal is the main source of mineralization fluids responsible for the economic system of wolfram veins (Ávila et al. [1]). Panasqueira mine has been laboring since 1896 and remains active, presently exploiting 3000 ton/day. Its long life has generated a significant environmental passive. Panasqueira is a source of tailings enriched by iron and sulphur in the form of sulphides - pyrite, chalcopyrite, arsenpyrite, galena, etc. In the mine area there are millions of tons of 
tailings and mine wastes in several stock piles. The zone is cut by creeks and small rivers that go to the Zezere river, which is the main source of drinkable water to the city of Lisbon.

It is important to know how this residues contribute to the acidification of the running water, as well as how it leachates heavy metals, which both seriously affect the environment, devastating biota living around the area.

\section{Acid Mine Drainage}

\subsection{AMD - generation}

Sulphide minerals are only thermodynamically stable in reduced conditions Eh lower than 0 Volts - because sulphur has a very low $(-2)$ oxidation number. So when they are exposed to oxygen and water they form oxides, hydroxides and carbonates. The mechanism of oxidation of sulphides, in particular of pyrite $\left(\mathrm{FeS}_{2}\right)$, is well studied, described by the equations:

$$
\begin{array}{ll}
2 \mathrm{FeS}_{2}+7 / 2 \mathrm{O}_{2} \rightleftharpoons \mathrm{Fe}^{2+}+2 \mathrm{SO}_{4}^{2-}+2 \mathrm{H}^{+} & \text {acid-generation and sulphate } \\
\mathrm{Fe}^{2+}+2 \mathrm{H}_{2} \mathrm{O} \rightleftharpoons \mathrm{FeOOH}+3 \mathrm{H}^{+} & \text {acid-generation and iron oxide } \\
\mathrm{Fe}^{2+}+1 / 4 \mathrm{O}_{2}+\mathrm{H}^{+} \rightleftharpoons \mathrm{Fe}^{3+}+1 / 2 \mathrm{H}_{2} \mathrm{O} & \text { iron oxidation }
\end{array}
$$

This $\mathrm{Fe}^{3+}$ is used in oxidation of other sulphide minerals, as sphalerite $(\mathrm{ZnS})$ or galena $(\mathrm{PbS})$, or of more pyrite

$$
\begin{array}{ll}
\mathrm{FeS}_{2}+14 \mathrm{Fe}^{3+}+8 \mathrm{H}_{2} \mathrm{O} \rightleftharpoons 15 \mathrm{Fe}^{2+}+2 \mathrm{SO}_{4}^{2-}+16 \mathrm{H}^{+} & \text {acid-generation and sulphate } \\
\mathrm{Fe}^{3+}+2 \mathrm{H}_{2} \mathrm{O} \rightleftharpoons \mathrm{FeOOH}+3 \mathrm{H}^{+} & \text {acid-generation and iron oxide }
\end{array}
$$

Sulphide dissolution kinetics depend directly on a large number of factors: oxidation rate of sulphides present (each sulphide mineral has a different oxidation rate, mineral surface area, particle size); reactions of immobilization and remobilization throughout the trajectory; water flux involved; redox potential (oxygen concentration); $\mathrm{pH}$; biologic activity. $\mathrm{pH}$ is in turn determined by the kinetic of oxidation reactions of the sulphides and of neutralizing reactions. If the waste contains minerals which effect neutralizing such as carbonates, the acid produced in the previous reactions is consumed as illustrated by the typical reaction of the acid with calcite:

$$
\mathrm{CaCO}_{3(s)}+2 \mathrm{H}^{+} \rightarrow \mathrm{Ca}^{2+}+\mathrm{CO}_{2(g)}+\mathrm{H}_{2} \mathrm{O}
$$

A natural production of acid exists when the sulphide minerals are in contact with the atmosphere (oxygen and water) and there aren't enough acid neutralizing minerals. This can occur for any type of ore deposit. Moreover the destination of metals depends on $\mathrm{pH}$, redox conditions and oxidation velocity of the sulphides. Figure 1 symbolically represents the possible interactions in the formation process and consumption of acid. 


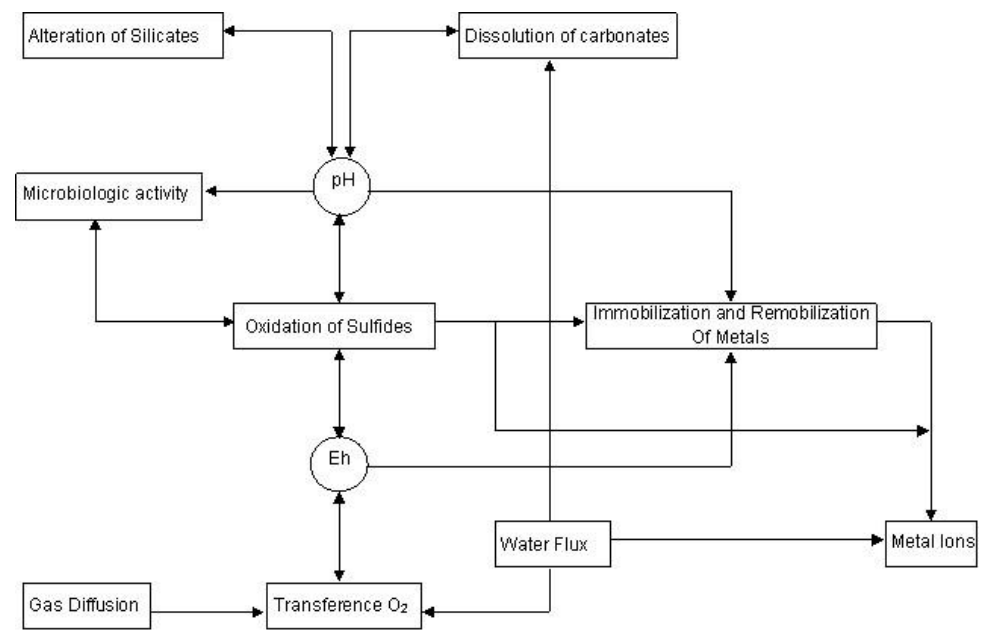

Figure 1: AMD generation and consumption scheme.

\subsection{Prevention and remediation strategies}

Given the practical difficulties in inhibiting the formation of AMD in the source, the alternative is to minimize its impact on receiving streams and rivers, and environment. Most of the preventive methods put the emphasis in minimizing sulphides oxidation rate. It can be done several ways, however the most widely used is to put a barrier that minimizes oxygen transport. Usually dry or wet covers are used for tailings, but a third type can be added: a oxygen consuming cover. Other possible methods are: addition of mineral neutralizing, sulphides removal, minimization of bacterial activity or the minimization of surface available to the weathering. The main methods used are:

Wet cover or underwater storage water is used as a barrier to oxygen diffusion, because it is about 104 times less than water diffusion in air;

Dry cover a low permeability cover with increased moisture is used as barrier to oxygen diffusion. The cover is usually made of clay;

Oxygen consuming cover uses a dry cover, as barrier to the diffusion of the oxygen, adding a high concentration of organic substance that, when degraded, consumes oxygen, reducing its transport;

Rising water table the materials are kept below water by raising the underground water level; This is done by increasing infiltration and reducing evaporation;

Blending addition of chemical-neutralizing agents or neutralizing minerals, that consume generated acid, keeping $\mathrm{pH}$ near neutrality;

Selective storage tailings are stored according to composition and properties, taking in consideration the generating capacity of acid;

Removal of Pyrite Pyrite is removed from the tailings and stored separately (for instance, under water). 
When the action of the weathering agents cannot be prevented it is necessary to control the acid migration, minimizing its transport and dispersion in the environment. Some of the available methods are: effluents collection, ground water flow control, use of impermeable covers. The leachate has to be treated before it produces negative impacts. The methods can be passive, such as the conduction of leachate through anoxic limestone drains, or active such as the neutralization by addition of lime. But the cost of one such operation, during a lapse of indeterminate time, is indefinite. Also, the volume of generated tailings continues increasing, placing problems of storage with inherent problems of chemical and potential stability. To select a remediation technique it is necessary to pay attention to the tailings deposition method. It depends on the tailings properties (chemical composition, particle size, moisture content) as well as site conditions (geologic, hydrogeologic, hydrographic, topographic, climatic). Prevention actions have as main objective to avoid the contact between mineral matter and dissolved oxygen (Johnson and Hallberg [2]).

\section{Methodology and methods}

Predictive tests aim at determining if a discrete volume of tailings will generate acid and at predicting the quality of the drainage based on the rate of acid formation [3]. To evaluate the acid generation potential two main types of analytic tests are used: static tests and kinetics tests. Their reliability is often far from the desirable, however, as it depends on sample collection and on the lab method adopted.

\subsection{Static tests}

Static tests allow to determine the maximum acid production potential (AP) which is a direct or indirect measure of sulphur, and the maximum neutralization potential (NP) which is a measure of the carbonate material available to neutralize acid. The difference between NP and AP gives the net neutralization potential (NPP = NP-AP). If the value of NPP is negative it means that the AP is greater than NP and there exists a real potential to form acid. On the other hand, if NPP is positive i.e. the carbonate content is enough to neutralize acid, the risk to form acid is lower. However, for values of NPP in the range -20 to 20, prediction of acid potential is difficult (Fiúza [4]). Acid production potential can also be described by the neutralization potential to acid production potential (NP/AP) ration. If it is greater than $3: 1$, there is a lower risk for acid drainage to develop; ratios of 1:1 or less are more likely to generate acid; ratios between $3: 1$ to $1: 1$ indicate an uncertainty zone and kinetic tests are recommended.

\subsection{Kinetic tests}

Kinetic tests are different from static tests in that they attempt to model natural oxidation reactions. These tests provide information about the kinetic of sulphide 
mineral oxidation and therefore of acid production, as well as of drainage water quality. Tailings samples are submitted to specified conditions (temperature, oxygen concentration, rate of infiltration, humidity) and the leachate produced is analyzed periodically allowing to infer the rate at which the reactions are occurring. There are the following kinetic tests:

Humidity cell test a $200 \mathrm{~g}$ sample crushed to minus $2.38 \mathrm{~mm}$ is leached in an enclosed container. The test is run for ten weeks and follows a seven day cycle. The sample may be inoculated with bacteria. During the seven day cycle, dry air is passed through the sample container for the first three days and humidified air for the next three days. On the seventh day the sample is rinsed with $200 \mathrm{~mL}$ of distilled water. The solution may be analyzed for $\mathrm{pH}$, acidity, alkalinity, and specific conductance; redox potential (the oxidationreduction potential of an environment), sulfate, and dissolved metals may also be tested;

Soxhelet extraction test it simulates geochemical weathering using a soxhelet extraction apparatus to recirculate solution through the sample;

Column tests are conducted by stacking the waste in a cylinder or similar device. Wetting and drying cycles are created by adding water and then allowing the column to dry. Each of the cycles may occur over a period of several days to a week or more, though they typically last for three days each. Water added to the column is collected and analyzed to determine the current oxidation rate, sulfate production, metal release, and other parameters [3];

The British Columbia Research Confirmation Test it is intended to determine if bacteria can catalyze enough reactions to satisfy their acid demands. It has the disadvantage of ignoring neutralization potential and sulfide oxidation rates, being less reliable than the other kinetics tests;

The batch reactor or shake flasks is relatively simple and allows examination of multiple factors, such as $\mathrm{pH}$ and temperature, which can be tested simultaneously. The influence of bacteria and control measures may be used as test parameters.

Field scale tests they are very different from laboratory tests where the experiment is conducted under controlled conditions. Sample size varies and may be as large as 1000 metric tons, depending on space availability. Particle size of the test material is not usually reduced for the test to better approximate field conditions. The sample is loaded on an impervious liner to collect solutions and a tank is used to collect the leachate. The volume of solution is determined and an aliquot is analyzed for $\mathrm{pH}$, sulfate, dissolved metals, and other parameters.

\subsection{Sample collection}

The sample was collected, during a two month period, at the final sampling point of the mineral processing plant of Panasqueira, ahead of the dam. A daily quantity of twenty kilograms was collected, dried and stored in closed containers. It was 
later homogeneously divided by different portions depending on the needs of subsequent tests.

\subsection{Laboratory tests}

Tailings were submitted to preliminary laboratory characterization tests namely: particle size analysis, $\mathrm{pH}$, moisture content and density.

\subsubsection{Conventional tests}

Panasqueira tailings were tested in a previous stage of this work by R. Lozano, 2007 [5]. The acid production potential (APP) and the neutralization potential (NP) were evaluated under EPA's specifications. A sample of $500 \mathrm{mg}$ of tailings reacted to $20 \mathrm{ml}$ of $1 \mathrm{~N}$ chloride acid; the resulting solution was filtered and titrated in a buffer solution of sodium hydroxide, allowing calculation of carbonate concentration and consequently of acid production potential (Lozano, [5]). Kinetics tests, a soxhelet test and a column test were also made. In the soxhelet test $100 \mathrm{~g}$ of solid sample was put in a flask, with distilled water as the main solvent and kept at a constant temperature of $100^{\circ} \mathrm{C}$ in order to generate steam which ascends through the condenser-extractor system. A sample was collected every 24 hours for $\mathrm{pH}$, conductivity, salinity and total solids in suspension determinations. The column test was performed on $150 \mathrm{~g}$ of solids and $250 \mathrm{ml}$ of distilled water in 15 cycles of wet/dry 3 days periods. After each wet period the liquid was collected and analyzed and the solids entered a three day dry period. The results of these tests were quite dubious, suggesting soxhelet tests are inadequate, and the need for modifying wet and dry periods in column tests as described in the following item.

\subsubsection{Modified column tests}

The modified column test was conducted in two similar columns $(3 \mathrm{~cm}$ diameter by $40 \mathrm{~cm}$ height). Column 1 containing $150 \mathrm{~g}$ of residues and column 2 containing also an organic cover layer of approximately $3 \mathrm{~cm}$. The wet/dry periods were of 5 days wet and 10 days dry. The extension of the dry period was due to the tailings particle size being very fine, causing very low percolation velocity, making 3 days an insufficient period to drain all the water in the column. On the other hand, a drying period bigger than the wet period is more realistic and describes better the local climatic conditions (the periods of rain are less and shorter than the periods without rain).

\subsection{Pilot scale tests}

In the outdoor place chosen for the tests were installed three columns of two plastic, one square meter base, containers, the top one grooved and lined with a textile drain in the sidewalls and in the bottom, to store Panasqueira tailings sample and to collect rain, and the bottom one closed to collect leachates. The distribution of the residues in the containers was made manually in order to guaranty its homogenization. This was confirmed by chemical analysis made in situ with a 

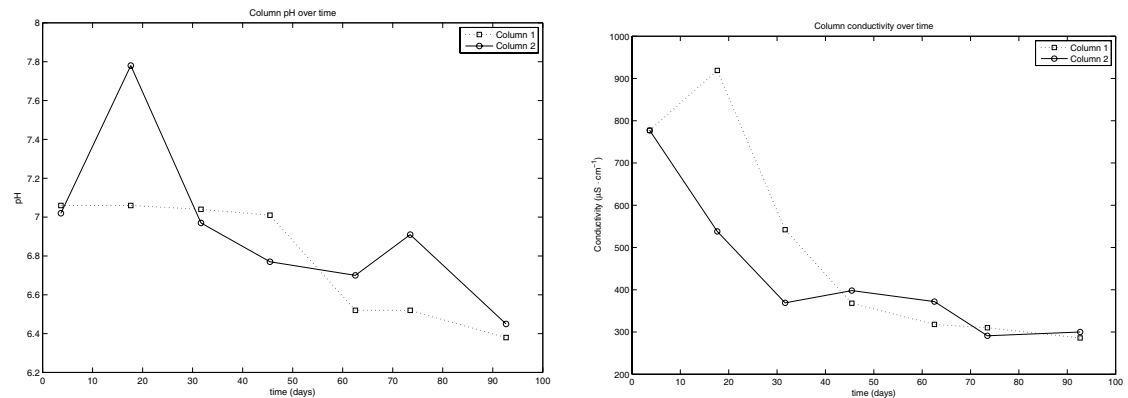

Figure 2: Time evolution of column $\mathrm{pH}$ and conductivity.

portable X-ray fluorescence apparatus. The container 1 was filled with simple residues; the container 2 had an additional cover layer of $5 \mathrm{~cm}$ organic compound (Agronat); the residues in container 3 were covered by a fine (approximately 2 $\mathrm{cm}$ ) layer of clay. In container 2 we study the delay in the oxidation of pyrite caused by the consumption of oxygen by aerobic microorganisms. In container 3 we look for a delay in the passage of rain water, lowering the permeability of the material. This setup was installed in October 2007, and is intended to stay for six months in order to endure different weather conditions. When it rains, all the leachate are collected from each container and are analyzed $(\mathrm{pH}$, conductivity, suspended solids, salinity). The temperature of residues is measured four or five days a week. Continuous local atmospheric conditions measures are downloaded from nearby weather stations. Chemical composition of the tailings were measured at the beginning of the test and after 80 days. All the leachate collected was stored and is being analyzed for different time storage.

\section{Results}

\subsection{Laboratory tests}

Although the static tests indicated the need for more studies, they revealed that Panasqueira tailings have a considerable acid production potential, which was confirmed by the modified column test, as shown in figure 2 in which it is possible to observe two different rates, in both $\mathrm{pH}$ and conductivity, before and after 40 days. In the first forty days $\mathrm{pH}$ decreases at a slower rate than after. On the contrary, conductivity decreases faster in the first period. The effect of organic cover, in column 2 , is almost imperceptible.

\subsection{Pilot scale tests}

Results of pilot scale tests for the leachate in general agreed with the column tests. Conductivity and $\mathrm{pH}$ are decreasing over time, and it is possible to identify a period of approximately 40 days after which $\mathrm{pH}$ and conductivity decrease at a constant 


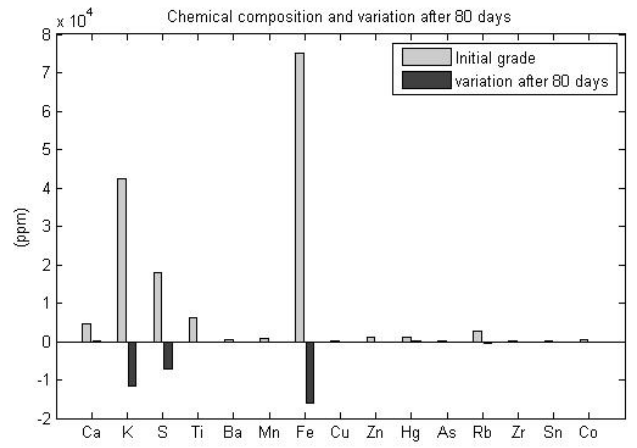

Figure 3: Chemical composition of tailings
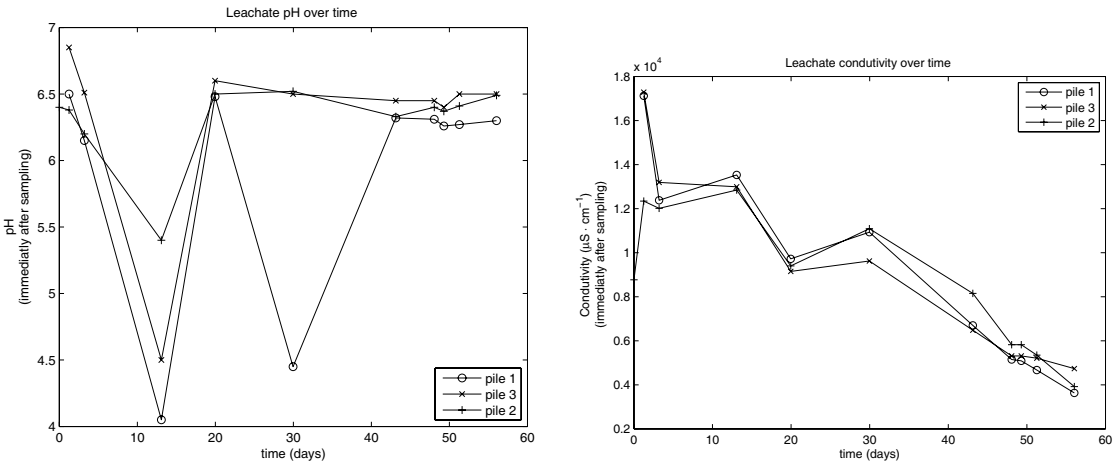

Figure 4: Time evolution of pile leachate $\mathrm{pH}$ and conductivity.

rate. It is important to note the fact that the $\mathrm{pH}$ of every pile leachate continues steeply decreasing, denoting acid runoff generation and biological action. This is confirmed by the decrease in iron and sulphur content in piles. Another useful information given by the pilot scale tests is that both covers contribute to a delay of acid generation, and covers effect starts at 40 days after the test begins.

\section{Conclusions}

Mining residues differ considerably from site to site, however they constitute a mid to long term source of contamination of soils and groundwater in its vicinities. Acid mine drainage in Panasqueira was confirmed by modified column tests as well by pilot scale tests. Pilot scale tests results are more reliable than laboratory ones. Based on this tests it is possible to predict the time required to acid production of these tailings in contact with air and rain water. 


\section{Acknowledgements}

This research work was supported by FCT-MCTES. Authors acknowledge the contribution of Eduardo Crespo from Panasqueira mine and Mário Machado Leite from INETI.

\section{References}

[1] Ávila, P., da Silva, E.F. \& Farinha, J.A., Geochemical signature of mining industry in the surrounding environment of panasqueira mine (Portugal). Proc. of the IMWA Symposium, Cagliari, pp. 27-30, 2007.

[2] Johnson, D.B. \& Hallberg, K., Acid mine drainage remediation options: a review. Science of the total environment, (338), pp. 3-14, 2005.

[3] EPA, Acid mine drainage prediction. Technical Report EPA530-R-94-036, U.S. Environmental Protection Agency, 1994.

[4] Fiúza, A., Previsão da drenagem ácida, 2005. Texto do curso de Ingeneria de la Restauracion do Programa Internacional Master: Aprovechamiento Sostenible de los Recursos Minerales.

[5] Lozano, R.M., Estudio de componentes biológicos de la fenomenologia de generation de drenaje acido de minas, utilizando la tecnica de respirometria. Master's thesis, Faculdade de Engenharia da Universidade do Porto, 2007. 